\title{
Spectrum of phenotypic anomalies in four families with deletion of the SHOX enhancer region
}

\author{
Valentina Gatta ${ }^{1,2^{*}+}$, Chiara Palka ${ }^{2,3+}$, Valentina Chiavaroli ${ }^{2,3}$, Sara Franchi ${ }^{2}$, Giovanni Cannataro ${ }^{4}$, Massimo Savastano ${ }^{4}$, \\ Antonio Raffaele Cotroneo ${ }^{4}$, Francesco Chiarelli, ${ }^{2,3}$, Angelika Mohn ${ }^{2,3}$ and Liborio Stuppia ${ }^{1,2}$
}

\begin{abstract}
Background: SHOX alterations have been reported in $67 \%$ of patients affected by Léri-Weill dyschondrosteosis $(L W D)$, with a larger prevalence of gene deletions than point mutations. It has been recently demonstrated that these deletions can involve the SHOX enhancer region, rather that the coding region, with variable phenotype of the affected patients.

Here, we report a SHOX gene analysis carried out by MLPA in 14 LWD patients from 4 families with variable phenotype.

Case presentation: All patients presented a SHOX enhancer deletion. In particular, a patient with a severe bilateral Madelung deformity without short stature showed a homozygous alteration identical to the recently described $47.5 \mathrm{~kb}$ PAR1 deletion. Moreover, we identified, for the first time, in three related patients with a severe bilateral Madelung deformity, a smaller deletion than the $47.5 \mathrm{~kb}$ PAR1 deletion encompassing the same enhancer region (ECR1/CNE7).
\end{abstract}

Conclusions: Data reported in this study provide new information about the spectrum of phenotypic alterations showed by LWD patients with different deletions of the SHOX enhancer region.

Keywords: Madelung deformity, MLPA, SHOX, Short stature

\section{Background}

SHOX deficiency represents a frequent cause of short stature, being associated with different pathological phenotypes such as Turner syndrome (TS), Idiopathic Short Stature (ISS; MIM ID 300582), Léri-Weill dyschondrosteosis (LWD; MIM ID 127300) and Langer mesomelic dysplasia (LS; MIM ID 249700) [1-10].

LWD is characterized by the presence of short stature associated with specific bone alterations, such as the Madelung deformity of the forearm. However, the fullblown LWD phenotype is frequently not determined in pre-schooler children because the specific features of this condition (i.e. mesomelic disproportion of the limbs and Madelung deformity), appears during the second decade of life [11-13]. As a consequence, in many cases short stature represents the only clinical sign at diagnosis. All together,

\footnotetext{
*Correspondence: v.gatta@unich.it

${ }^{\dagger}$ Equal contributors

'Department of Psychological, Humanities and Territory Sciences, School of Medicine and Health Sciences, "G. d'Annunzio" University of Chieti, via dei Vestini 31,66013 Chieti, Italy

${ }^{2}$ Center of Excellence on Aging, "G. d'Annunzio" University Foundation, via dei Vestini 31, 66013 Chieti, Italy

Full list of author information is available at the end of the article
}

mutations affecting the SHOX function in the different pathological conditions display an estimate frequency of less than 1:1000, thus representing the most common mendelian disease in the Caucasian population [14].

Due to this high frequency of alterations of the SHOX gene and to the recently demonstrated good response to the treatment with growth hormone $(\mathrm{GH})$ in patients with $S H O X$ deficiency, the early identification of SHOX alterations has become crucial for the diagnosis of the disease and the therapeutic strategy [15]. In this view, a phenotype scoring system assisting the identification of the most appropriate subjects for SHOX testing has been developed by Rappold et al. [16], recommending SHOX analysis in presence of a score greater than four out of a total possible score of 24. Moreover, Binder described an interesting algorithm approach to $S H O X$ mutation screening in short children, promoting the clinical diagnosis supported by an auxological analysis of the body proportions (mesomelia), the presence of minor abnormalities, and the search for subtle radiographic signs and the molecular studies for confirming clinical data [17].

A large number of literature reports have demonstrated the presence of SHOX alterations in about $67 \%$ 
of LWD cases $[18,19]$. On the other hand, SHOX alterations are not detected in the vast majority of cases with idiopathic short stature (85-98\%) $[9,17,20]$.

The use of the MLPA assay [18-21] has disclosed that deletions can involve not only the SHOX coding region, but also the upstream and downstream SHOX enhancer sequences [22-25].

Recently, Benito-Sanz et al. [26] provided a deep characterization of a relatively small deletion of PAR1, previously reported by Chen et al. [10] and Caliebe et al. [27], uncovering a novel downstream enhancer. This deletion is correlated with a remarkably variable phenotype of patients [28], confirming the evidence that deletion size is not related with the severity of the clinical phenotype [29], which, despite the high penetrance of $S H O X$ deficiency, is very variable becoming more pronounced with age and being more severe in females [17].

The identification of PAR1 deletions not involving the SHOX coding regions have raised novel interest to the knowledge of the mechanisms leading to short stature in cases with $S H O X$ deficiency.

In order to provide a contribute to this field of studies, we report on SHOX gene analysis in LWD patients with selected dysmorphic signs derived from four families, all evidencing deletions of the enhancer region, which was present in homozygous form in a patient with Madelung deformity but normal stature.

\section{Case presentation}

A written informed consent was obtained from each patient. The different techniques were performed according to standard procedures of the participating centers, with the purpose to reach a genetic diagnosis in the studied patient. It was not designed as an experimental study.

\section{Family 1}

The index case (Figure 1-n.1) was a 12-years and 10 months girl admitted to the outpatient Endocrine Clinic of the Department of Pediatrics, University of Chieti, Italy, for short stature. The girl was the first offspring of unrelated healthy parents. She has one 10year-old sister, who had a normal linear and ponderal growth. The girl was born after 39 weeks of gestation after an unremarkable pregnancy. Birth anthropometric measurements were the following: weight $2.500 \mathrm{~kg}\left(3^{\text {th }}-\right.$ $10^{\text {th }}$ percentile), length $48 \mathrm{~cm}\left(10^{\text {th }}-25^{\text {th }}\right.$ percentile $)$. From the first months of life she had slow linear and ponderal growth, with normal psychomotor development. At our first clinical evaluation she showed short stature $(140.6 \mathrm{~cm},-2.18 \mathrm{SDS})$. Sitting height was $75 \mathrm{~cm}$ (-2.0 SDS), sitting height/height ratio was $0.53(+1.0$ SDS) and arm span/height ratio was $96.7 \%$. BMI was between $25^{\text {th }}-50^{\text {th }}$ percentile and head circumference was

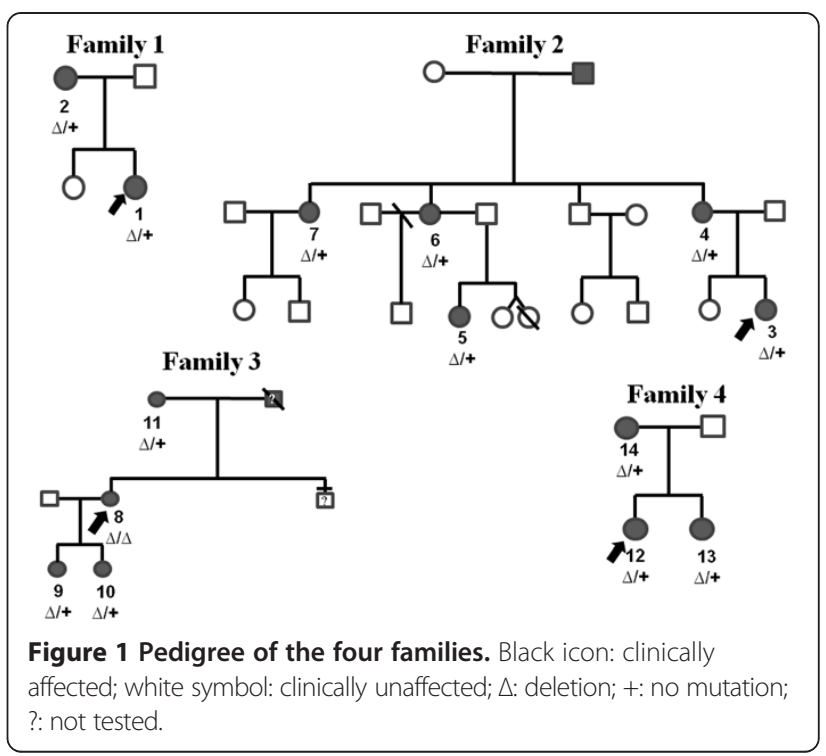

normal. She had mesomelia with muscular hypertrophy. No facial dysmorphism was detected except for mild webbed neck. Radiological examination of the forearms showed bilaterally slight triangular deformation of distal radial epiphysis and mild bowing of radial diaphysis; legs were normal. Bone age according to Greulich and Pyle was 13.8 yr. Based on the detected clinical and radiological signs, the total Rappold's score was 6 (Table 1).

The 49-year-old mother of the proband (Figure 1-n.2) also showed short stature (149 cm, -2.0 SDS). Sitting height was $72 \mathrm{~cm}(<-2.0 \mathrm{SDS})$, sitting height/height ratio was $0.48 \mathrm{~cm}(<-2.5 \mathrm{SDS})$ and arm span/height ratio was $93 \%$. BMI was $>50^{\text {th }}$ percentile. She had mesomelia with muscular hypertrophy. No facial dysmorphisms were detected except for mild webbed neck. Radiological examination of the radius and ulna showed bilateral Madelung deformity; legs were normal. The total Rappold's score was 12 (Table 1).

\section{Family 2}

The index case (Figure 1-n.3) was a 3-years and 11 months girl admitted to the outpatient Endocrine Clinic of the Department of Pediatrics, University of Chieti, Italy, for short stature. The girl was the second offspring of unrelated healthy parents. She has one 6-year-old healthy sister, showing normal linear and ponderal growth. The girl was born after 38 weeks of gestation after an unremarkable pregnancy. Birth anthropometric measurements were the following: weight $2.820 \mathrm{~kg}\left(10^{\text {th }}-25^{\text {th }}\right.$ percentile), length $48.5 \mathrm{~cm}\left(25^{\text {th }}-50^{\text {th }}\right.$ percentile). From the first months of life she had slow linear growth, whereas ponderal growth and psychomotor development were normal. At our first clinical evaluation she showed short stature $(91.3 \mathrm{~cm},-2.53$ SDS). Sitting height was $72.6 \mathrm{~cm}(<-2.5 \mathrm{SDS})$, sitting height/height 
Table 1 Clinical characteristics of 14 patients with a deletion in the downstream enhancer region of SHOX

\begin{tabular}{|c|c|c|c|c|c|c|c|c|c|c|c|}
\hline Patient & Age(sex) & Shox deletion (mlpa probes) & $\begin{array}{l}\text { Arm Span/Height } \\
\text { ratio }(<96.5 \%)\end{array}$ & $\begin{array}{l}\text { Sitting height/Height } \\
\text { ratio }(>55.5 \%)\end{array}$ & $\begin{array}{c}\mathrm{BMI} \\
\left(>50^{\circ} \mathrm{C}\right)\end{array}$ & $\begin{array}{l}\text { Cubitus } \\
\text { Valgus }\end{array}$ & $\begin{array}{c}\text { Short } \\
\text { forearm }\end{array}$ & $\begin{array}{l}\text { Bowing } \\
\text { forearm/ } \\
\text { tibia }\end{array}$ & $\begin{array}{l}\text { Muscular } \\
\text { hypertrophy }\end{array}$ & $\begin{array}{l}\text { Dislocation of } \\
\text { ulna at the elbow }\end{array}$ & $\begin{array}{l}\text { Total } \\
\text { score }\end{array}$ \\
\hline \multicolumn{12}{|c|}{ FAMILY 1} \\
\hline$n .1$ & $12 \mathrm{y} 10 \mathrm{~m}(\mathrm{~F})$ & $\begin{array}{l}\text { heterozygous del 13296-L15336, } \\
\text { 05645-L05099 and 05646-L15507 }\end{array}$ & $96.7 \%(0)$ & $53 \%(0)$ & $<50^{\circ} \mathrm{C}(0)$ & Absent (0) & Present (3) & Absent (0) & Present (3) & Absent (0) & 6 \\
\hline$n .2$ & $49 y(F)$ & $\begin{array}{l}\text { heterozygous del 13296-L15336, } \\
\text { 05645-L05099 and 05646-L15507 }\end{array}$ & $93 \%(2)$ & $48 \%(0)$ & $>50^{\circ} \mathrm{C}(4)$ & Absent (0) & Present (3) & Absent (0) & Present (3) & Absent (0) & 12 \\
\hline \multicolumn{12}{|c|}{ FAMILY 2} \\
\hline$n .3$ & $3 y 11 \mathrm{~m}(\mathrm{~F})$ & $\begin{array}{l}\text { heterozygous del 13296-L15336, } \\
\text { 05645-L05099 and 05646-L15507 }\end{array}$ & $100 \%(0)$ & $53 \%(0)$ & $>50^{\circ} \mathrm{C}(4)$ & Present (2) & Present (3) & Absent (0) & Present (3) & Absent (0) & 12 \\
\hline n.4 & $39 y(F)$ & $\begin{array}{l}\text { heterozygous del 13296-L15336, } \\
\text { 05645-L05099 and 05646-L15507 }\end{array}$ & $98 \%(0)$ & $41.9 \%(0)$ & $>50^{\circ} \mathrm{C}(4)$ & Present (2) & Present (3) & Absent (0) & Present (3) & Absent (0) & 12 \\
\hline n.5 & $10 y(F)$ & $\begin{array}{l}\text { heterozygous del 13296-L15336, } \\
\text { 05645-L05099 and 05646-L15507 }\end{array}$ & $100 \%(0)$ & $47.8 \%(0)$ & $>50^{\circ} \mathrm{C}(4)$ & Present (2) & Present (3) & Absent (0) & Present (3) & Absent (0) & 12 \\
\hline$n .6$ & $46 y(F)$ & $\begin{array}{l}\text { heterozygous del 13296-L15336, } \\
\text { 05645-L05099 and 05646-L15507 }\end{array}$ & $98 \%(0)$ & $47.2 \%(0)$ & $<50^{\circ} \mathrm{C}(0)$ & Present (2) & Present (3) & Absent (0) & Present (3) & Absent (0) & 8 \\
\hline$n .7$ & $48 y(F)$ & $\begin{array}{l}\text { heterozygous del 13296-L15336, } \\
\text { 05645-L05099 and 05646-L15507 }\end{array}$ & $96 \%(2)$ & $49 \%(0)$ & $>50^{\circ} \mathrm{C}(4)$ & Absent (0) & Present (3) & Absent (0) & Present (3) & Absent (0) & 12 \\
\hline \multicolumn{12}{|c|}{ FAMILY 3} \\
\hline$n .8$ & $30 y(F)$ & $\begin{array}{l}\text { homozygous del 13296-L15336, } \\
\text { 05645-L05099 and 05646-L15507 }\end{array}$ & $98 \%(0)$ & $54 \%(0)$ & $<50^{\circ} \mathrm{C}(0)$ & Present (2) & Present (3) & Present (3) & Present (3) & Present (5) & 16 \\
\hline$n .9$ & $2 \mathrm{y} 10 \mathrm{~m}(\mathrm{~F})$ & $\begin{array}{l}\text { heterozygous del 13296-L15336, } \\
\text { 05645-L05099 and 05646-L15507 }\end{array}$ & $94 \%(2)$ & $56.9 \%(2)$ & $<50^{\circ} \mathrm{C}(0)$ & Absent (0) & Present (3) & Absent (0) & Absent (0) & Absent (0) & 7 \\
\hline n.10 & $11 \mathrm{~m}(\mathrm{~F})$ & $\begin{array}{l}\text { heterozygous del 13296-L15336, } \\
\text { 05645-L05099 and 05646-L15507 }\end{array}$ & $94 \%(2)$ & $58.3 \%(2)$ & $<50^{\circ} \mathrm{C}(0)$ & Absent (0) & Present (3) & Absent (0) & Absent (0) & Absent (0) & 7 \\
\hline$n .11$ & $54 \mathrm{y}(\mathrm{F})$ & $\begin{array}{l}\text { heterozygous del 13296-L15336, } \\
\text { 05645-L05099 and 05646-L15507 }\end{array}$ & $100 \%(0)$ & $52 \%(0)$ & $<50^{\circ} \mathrm{C}(0)$ & Present (2) & Present (3) & Absent (0) & Present (3) & Absent (0) & 8 \\
\hline \multicolumn{12}{|c|}{ FAMILY 4} \\
\hline n.12 & $14,7 y(F)$ & heterozygous del 05645-L05099 & $97 \%(0)$ & $50 \%(0)$ & $>50^{\circ} \mathrm{C}(4)^{\circ}$ & Present (2) & Absent (0) & Absent (0) & Present (3) & Absent (0) & 9 \\
\hline n.13 & $11 y(F)$ & heterozygous del 05645-L05099 & $97 \%(0)$ & $48 \%(0)$ & $>50^{\circ} \mathrm{C}(4)$ & Present (2) & Absent (0) & Absent (0) & Present (3) & Absent (0) & 9 \\
\hline n.14 & $42 y(F)$ & heterozygous del 05645-L05099 & $93 \%(2)$ & $50 \%(0)$ & $>50^{\circ} \mathrm{C}(4)$ & Absent (0) & Present (3) & Absent (0) & Present (3) & Absent (0) & 12 \\
\hline
\end{tabular}


ratio was $0.53(-1.2 \mathrm{SDS})$ and arm span/height ratio was $100 \%$. BMI was $>95^{\text {th }}$ percentile. The habitus was muscular, and she had mesomelia and facial dysmorphisms, such as mild hypertelorism, left epicanthus, high-arched palate, mild webbed neck, cubitus and genu valgus and lordosis. At radiological examination left radius showed a mild bowing of diaphysis, triangularization of distal epiphysis and bowing of diaphysis of radius, radiolucency of distal radio-ulnar articulation with normality of left radius, ulnas and wrists (Figure 2E); legs were normal. Bone age according to Greulich and Pyle was 3 yr. The total Rappold's score was 12 (Table 1).
Her mother (Figure 1-n.4) (39-year-old) also showed short stature $(146.4 \mathrm{~cm},-2.43 \mathrm{SDS})$. Sitting height was $61.4 \mathrm{~cm}(<-2.5$ SDS), sitting height/height ratio was $41.9 \%$ and arm span/height ratio was $98 \%$. BMI was between $50^{\text {th }}-75^{\text {th }}$ percentile. Muscular hypertrophy was detected. She had mesomelia with facial dysmorphisms including mild high-arched palate and webbed neck. Mild scoliosis with cubitus and genu valgus were detected. The patient suffered from adolescence of diffuse muscular pain, which at adult age was imputed to fibromyalgia. Radiological examination showed triangularization of distal epiphysis and bowing of diaphysis of radius
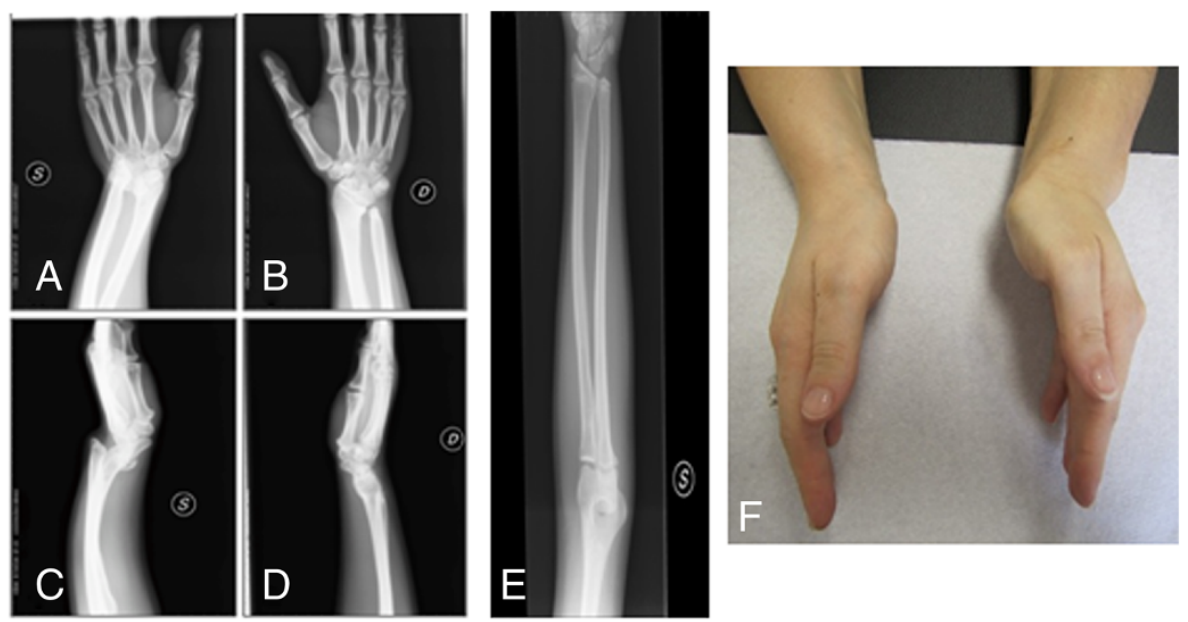

G

$\mathrm{H}$
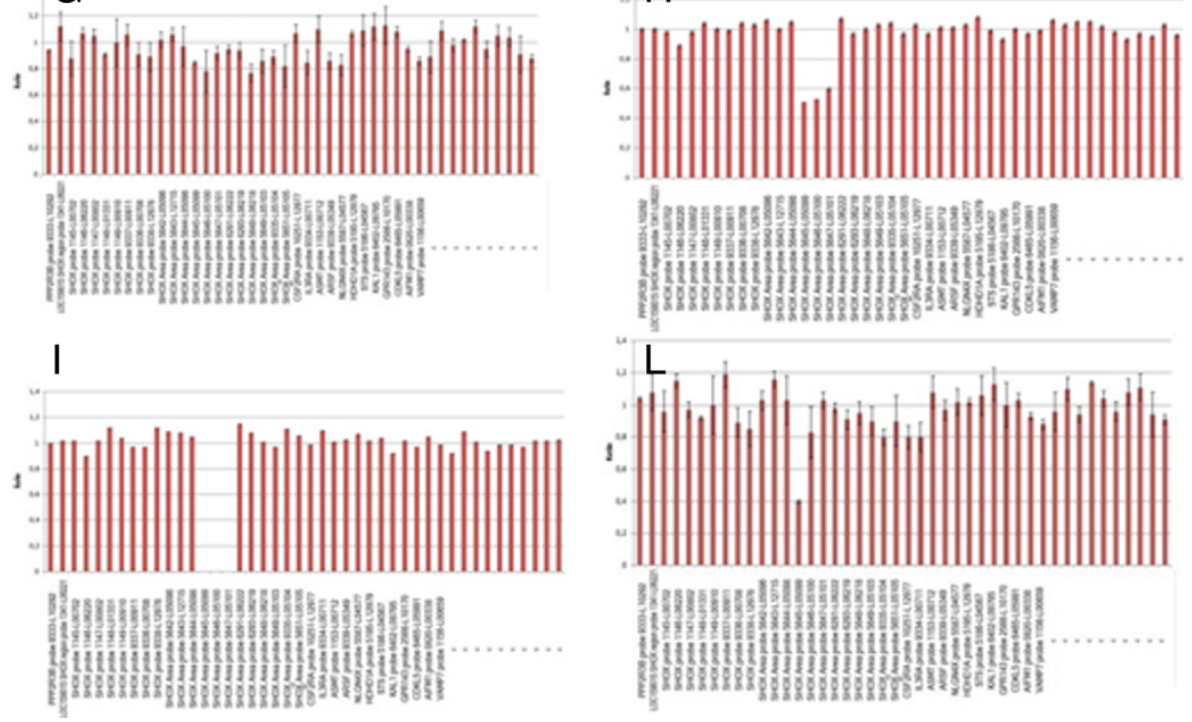

Figure 2 Female 39-year-old: Bilateral forearm radiographs show triangularization of distal epiphysis and bowing of diaphysis of radius bilaterally; distal radio-ulnar articulations appeared radiographically lucent. Palmar subluxation of the left carpus (A-D). Female 6-year-old: Left forearm radiography shows triangularization of distal epiphysis and bowing of diaphysis of radius, radiolucency of distal radio-ulnar articulation (E). Madelung deformity of family 3 index case (n.8) (F). The lower panel showes MLPA assay results. (G) Control: Normal peaks were classified as showing a ratio of 0.65-1.35 (H) Heterozygous deletion of the 13296-L15336, 05645-L05099 and 05646-L15507. MLPA probes have a ratio < 0.65. (I) Homozygous deletion of the 13296-L15336, 05645-L05099 and 05646-L15507 MLPA probes showing a ratio = 0. (L) Heterozygous deletion of the 05645-L05099 MLPA probes. 
bilaterally;distal radio-ulnar articulations appeared radiographically lucent and legs did not show skeletal anomalies (Figure 2A-D). The total Rappold's score was 12 (Table 1).

A 10-year-old cousin (Figure 1-n.5) of the index case was also admitted for short stature. The girl was the second offspring of unrelated healthy parents. She has one 18-year-old healthy brother and one 7-year-old healthy sister, both of them with normal linear and ponderal growth. The girl was born after 32 weeks of gestation after an unremarkable pregnancy. Birth anthropometric measurements were the following: weight $2.850 \mathrm{~kg}$ $\left(>97^{\text {th }}\right.$ percentile), length $45.2 \mathrm{~cm}\left(90^{\text {th }}-97^{\text {th }}\right.$ percentile). From the first months of life she had slow linear growth with normal ponderal growth. Psychomotor development was normal. At our first clinical evaluation she showed short stature $(125.3 \mathrm{~cm},-2.07 \mathrm{SDS})$. Sitting height was $60 \mathrm{~cm}(<-2.5 \mathrm{SDS})$, sitting height/height ratio was $47.8 \%$, arm span /height ratio was $100 \%$. BMI was between $85^{\text {th }}-90^{\text {th }}$ percentile. The habitus was slightly muscular, and she had mesomelia and facial dysmorphisms, including mild high-arched palate and mild webbed neck. She also had cubitus valgus and valgus knee. Bone age according to Greulich and Pyle was $8.6 \mathrm{yr}$. Radiological examination of the radius, ulnas and legs did not show significant bone alterations. The total Rappold's score was 12 (Table 1 ).

Her mother (Figure 1-n.6) (46-year-old), the sister of index case's mother, also showed mild linear impairment $(149.8 \mathrm{~cm},-1.86 \mathrm{SDS})$. Sitting height was $70.8 \mathrm{~cm}$ (<-2.5 SDS), sitting height/height ratio was $47.2(<-2.5$ SDS) and arm span /height ratio was $98 \%$. BMI was between $25^{\text {th }}-50^{\text {th }}$ percentile. The habitus was muscular, and she had mesomelia, cubitus valgus without facial dysmorphisms. The patient suffered from adolescence of diffuse muscular pain, which at adult age was imputed to fibromyalgia. Radiological examination showed bilaterally triangularization of distal epiphysis and bowing of diaphysis of radius, radiolucency of distal radio-ulnar articulation; legs were normal.The total Rappold's score was 8 (Table 1).

Another sister of index case's mother (Figure 1-n.7) (48-year-age old) also showed mild linear impairment $(150.4 \mathrm{~cm},-1.76$ SDS). Sitting height was $75 \mathrm{~cm}(<-2.5$ SDS), sitting height/height ratio was $49(<-2.25$ SDS $)$ and arm span /height ratio was $96 \%$. BMI was between $85^{\text {th }}-95^{\text {th }}$ percentile. The habitus was muscular, and she had mesomelia. The patient suffered from adolescence of diffuse muscular pain, which at adult age was imputed to fibromyalgia. Radiological examination of the radius and ulna showed bilateral Madelung deformity. The total Rappold's score was 12 (Table 1).

\section{Family 3}

The index case (Figure 1-n.8) was a 30-year-old women admitted to the outpatient Genetic Clinic, University of
Chieti, Italy, for Madelung deformity surgically corrected at the age of 18 (Figure 2F). The women was the second offspring of unrelated healthy parents. She has one 26year-old healthy brother, who had a normal linear and ponderal growth. The women was born at term after an unremarkable pregnancy. Birth anthropometric measurements were in the normal rage. From the first months of life she had slow linear growth with normal ponderal growth and psychomotor development. At our first clinical evaluation she did not show short stature $(155.6 \mathrm{~cm},-0.89$ SDS). Sitting height was $84 \mathrm{~cm}(<-2.5$ SDS), sitting height/height ratio was $54 \%(<-2.5$ SDS $)$ and arm span/height ratio was $98 \%$. BMI was between $25^{\text {th }}-50^{\text {th }}$ percentile. The habitus was muscular, and she had mesomelic, facial dysmorphisms (hypertelorism) and cubitus and genu valgus with scoliosis. The patient suffered from adolescence of diffuse muscular pain. Radiological examination of the radius and ulna showed bilateral Madelung deformity (Figure 2F). The total Rappold's score was 16 (Table 1).

This patient had two daughters. The first girl (Figure 1n.9) was born after 37 weeks of gestation after an unremarkable pregnancy. Birth anthropometric measurements were the following: weight $2.560 \mathrm{~kg}\left(10^{\text {th }}-25^{\text {th }}\right.$ percentile), length $49.5 \mathrm{~cm}\left(75^{\text {th }}-90^{\text {th }}\right.$ percentile). She showed decrease of linear growth from the age of 21 months, while poor ponderal growth was detected from the age of 1 year. Psychomotor development was normal. At our first clinical evaluation she was 2-years and 10 months old. She showed short stature $(87 \mathrm{~cm},-2.09 \mathrm{SDS})$. Sitting height was $49 \mathrm{~cm}(<-2.5 \mathrm{SDS})$, sitting height/height ratio was $56.9 \%(<-2.0$ SDS $)$ and arm span/height ratio was $94 \%$. BMI was at $10^{\text {th }}$ percentile. Head circumference was normal. The habitus was not muscular, and she had mesomelia and facial dysmorphisms, including hypertelorism, epicanthus and mild webbed neck. Bone age according to Greulich and Pyle was 2.5 yr. Radiological examination of the forearms was normal.The total Rappold's score was 7 (Table 1).

The second girl (Figure 1-n.10) was born after 37 weeks of gestation after an unremarkable pregnancy. Birth anthropometric measurements were the following: weight $2.430 \mathrm{~kg}\left(3^{\text {th }}-10^{\text {th }}\right.$ percentile), length $46 \mathrm{~cm}\left(10^{\text {th }}-25^{\text {th }}\right.$ percentile). She showed poor linear and ponderal growth from the age of six months. Psychomotor development was normal.At our first clinical evaluation she was 11month-old. She showed short stature $(72 \mathrm{~cm},-4.11 \mathrm{SDS})$. Sitting height was $42 \mathrm{~cm}(<-2.5$ SDS), sitting height/ height ratio was $58.3 \%(<-2.5$ SDS) and arm span/height ratio was $94 \%$. BMI was at $10^{\text {th }}$ percentile. Head circumference was normal.The habitus was not muscular. She did not show mesomelia but facial dysmorphisms were detected, including epicanthus, hypertelorism and mild webbed neck. Bone age according to Greulich and Pyle 
was 1 yr. Radiological examination of the radius and ulna was normal.The total Rappold's score was 7 (Table 1).

The index case's mother (Figure 1-n.11) (54 year-old) did not show short stature $(159 \mathrm{~cm},-0.32$ SDS). Sitting height was $75 \mathrm{~cm}(<-2.5 \mathrm{~cm})$, sitting height/height ratio was $52 \%(<-2.5$ SDS $)$ and arm span/height ratio was $100 \%$. BMI was between $25^{\text {th }}-50^{\text {th }}$ percentile. The habitus was muscular, and she had mesomelia with facial dysmorphisms (hypertelorism) and mild scoliosis. Radiological examination of the radius and ulna showed bilateral Madelung deformity, with left ulnar dorsal dislocation. The total Rappold's score was 8 (Table 1).

\section{Family 4}

The index case (Figure 1-n.12) was a 14-years and 7 months girl admitted to the outpatient Endocrine Clinic of the Department of Pediatrics, University of Chieti, Italy, for short stature. The girl was the first offspring of unrelated healthy parents. She was born after 40 weeks of gestation after an unremarkable pregnancy. Birth anthropometric measurements were the following: weight $3.180 \mathrm{~kg}\left(25^{\text {th }}-50^{\text {th }}\right.$ percentile), length $48 \mathrm{~cm}$ $\left(10^{\text {th }}-25^{\text {th }}\right.$ percentile). From the first months of life she had slow linear and ponderal growth, with normal psychomotor development. At our first clinical evaluation she showed short stature $(147.6 \mathrm{~cm},-1.79$ SDS). Sitting height was $75 \mathrm{~cm}(-2.5 \mathrm{SDS})$, sitting height/height ratio was $0.50(-2.0 \mathrm{SDS})$ and arm span/height ratio was $97 \%$. BMI was between $50^{\text {th }}-75^{\text {th }}$ percentile and head circumference was normal. She had mild webbed neck, muscular hypertrophy, pectus carenatum, and cubitus and genu valgus. Radiological examination of the radius and ulna showed bilateral Madelung deformity. Bone age according to Greulich and Pyle was 16 yr. Based on the detected clinical and radiological signs, the total Rappold's score was 9 (Table 1 ).

The sister of the proband (Figure 1-n.13) (11-year-old) showed a normal linear growth $(138 \mathrm{~cm},-1.0$ SDS), sitting height was $67 \mathrm{~cm}(<-2.5 \mathrm{SDS})$, sitting height/height ratio was $0.48 \mathrm{~cm}(<-2.5 \mathrm{SDS})$ and arm span/height ratio was $97 \%$. BMI was $>85^{\text {th }}$ percentile. She had muscular hypertrophy, pectus carenatum, and cubitus and genu valgus. Radiological examination showed bilaterally triangularization of distal epiphysis and bowing of diaphysis of radius, correlated to Madelung deformity. Bone age according to Greulich and Pyle was 12 yr. The total Rappold's score was 9 (Table 1).

The mother of the proband (Figure 1-n.14) (42-yearold) also showed normal stature $(160.2 \mathrm{~cm},-0.12 \mathrm{SDS})$. Sitting height was $80 \mathrm{~cm}(<-2.5 \mathrm{SDS})$, sitting height/ height ratio was $0.50 \mathrm{~cm}(<-2.0 \mathrm{SDS})$ and arm span/ height ratio was $93 \%$. BMI was $>95^{\text {th }}$ percentile. She had mild mesomelia with muscular hypertrophy. No facial dysmorphisms were detected except for webbed neck.
The patient suffered from adolescence of diffuse muscular pain.Radiological examination of the radius and ulna showed bilateral Madelung deformity. The total Rappold's score was 12 (Table 1).

Laboratory investigations allowed us to exclude thyroid dysfunction, abnormal IGF-1 levels and celiac disease in all the investigated patients, which all had normal diploid karyotype.

\section{Molecular analysis}

Genomic DNA was extracted from peripheral blood or buccal swab by QIAamp DNA Blood Midi Kit (Qiagen, Hilden, Germany). SHOX deletions were detected using the MRC-Holland MLPA kit (Salsa P018-E and F1; MRC-Holland, Netherlands - Resnova, Italy) according to the manufacturer's instructions. The P018-D1 SHOX probemix contains 44 MLPA probes with amplification products between 130 and 463 nt. Seven of these probes are specific for each exon of the human SHOX gene and one is mapped just before the SHOX promoter region (4 kb before SHOX-PAR1). In addition, 14 probes are present detecting sequences in a region downstream of SHOX which has been implicated in regulation of SHOX transcription. Furthermore, nine probes on the $\mathrm{X}$ chromosome, out of PAR regions, are included in this probemix. Finally, ten autosomal reference probes are included. All the patients were also investigated with the last MLPA SHOX probemix (P018-F1) that as compared to oldest D1version three new probes near the PAR1 boundary have been included. Two probes (GPR143 and 13296-L15336) has been removed. The 88 and $96 \mathrm{nt}$ control fragments have been replaced (QDX2) (http:// www.mrc-holland.com). Data Analysis was performed using the Coffalyser software v. 9.4 (http://coffalyser. wordpress.com/).

In order to rule out false positive cases due to the presence of polymorphisms hampering the MLPA probe, we further investigated cases with deletion using PCR amplification with primers mapped within the probes region (SHOX_318 F: ACACCCAGTCATGAATGCAA; SHOX_318 R: CTTGGCTGGACAGACTCAGG; SHOX_ 432 F: ACATCGGCCTTTCCAAATAA; SHOX_432R: CTCGGGAGGCAGAGAGATTT), followed by direct sequencing on ABI 3130XL (ABI, Warrington, UK).

\section{Results}

MLPA analysis, carried out in the four index patients and their familiars $(\mathrm{N}=10)$, evidenced a heterozygous deletion of probes 13296-L15336, 05645-L05099 and 05646-L15507 (47543 bp deletion) in nine patients (patients 1-7, 9, 10) and a homozygous deletion of the same probes in the patient n. 8 (Figure $2 \mathrm{H}, \mathrm{I}$ ). A heterozygous deletion encompassing only the probe 05645-L05099 was revealed in three related patients (patients 12-14) 
(Figure 2L). All detected deletions involved a distinct SHOX enhancer region, not affecting the $S H O X$ coding region.

All the data were confirmed using the latest MLPA SHOX probemix (P018-F1). Since in this last probe mix version the probe 13296-L15336 was removed because not reliable, the $47543 \mathrm{pb}$ deletion was characterized by the absence of the remaining two MLPA probes 05645L05099 and 05646-L15507.

MLPA results were confirmed by PCR and DNA sequencing, showing absence of amplification in the patient with a homozygote deletion and absence of polymorphisms in all the observed heterozygous deletions.

\section{Discussion}

The SHOX gene belongs to a family of transcriptional regulators that are mainly expressed in the middle portion of the limbs where assure the correct balance between proliferation and apoptosis during bone development. The absence of wild type $S H O X$ would promote atypical proliferation of the chondrocytes combined with defective differentiation, leading to retarded longitudinal bone growth [30,31]. This specific pattern of expression can explain the wide phenotypic variability of SHOX deficiency patients with cases of normal stature but mesomelia and Madelung deformity.

In the present study we investigated SHOX region molecular defect in four LWD families, three of which showed the recurrent $\sim 47.5 \mathrm{~kb}$ PAR1 deletion, previously described by Benito-Sanz et. al [26]. This deletion is mapped downstream of the SHOX gene and contains an enhancer sequence (ECR1/CNE7). The deletion was present in heterozygous state in all the analyzed members except one case of homozygous deletion, which surprisingly presented severe bilateral Madelung deformity but a normal stature within her target height range.

The fourth analyzed family is of particular interest, since we found, for the first time, a heterozygous deletion encompassing only one of the three classical MLPA probes characterizing the recurrent - $47.5 \mathrm{~kb}$ PAR1 deletions. The rearrangement cosegregated with the LWD phenotype in all the members of the family, with a clinical phenotype similar to the one showed by cases with larger deletion, confirming a pathogenic effect also of this shorter enhancer deletion. Looking in detail at this group of 14 patients it appears evident that the phenotype of patients with deletions in the 3'-PAR1 region is remarkably variable and not related to the extension or the homozygous and heterozygous form. Up to date only a few studies have been performed concerning the phenotype showed by patients carrier of enhancer deletions, all suggesting a great variability $[7,28]$. Kant et al. described a case in which the enhancer deletion was associated with normal stature, although below the target height range [28].
In order to better assess the clinical expression in our cohort, we calculated the Rappold score of the investigated patients [16]. Interestingly, all patients had a score greater than 4 with a median value of 11.5 (range 6-13), but a great variability was found among the different clinical signs. In fact, short forearm and muscular hypertrophy were the two most observed dysmorphic abnormalities (100\% and $80 \%$, respectively), while cubitus valgus and $\mathrm{BMI}$ greater than $50^{\text {th }}$ percentile were less frequent (60\% and $40 \%$, respectively). Unexpectedly, arm span/height ratio and sitting height/height ratio were uncommon ( $30 \%$ and $20 \%$, respectively), whereas bowing of forearm and tibia as well as dislocation of ulna at the elbow were present only in one subject (Table 1).

The results obtained from the study of these four families suggest that, even if all the patients were eligible for the SHOX molecular analysis, some of the Rappold criteria are not very distinctive for SHOX deficiency. In fact, we had to take into account other characteristics, such as Madelung deformity, found in $60 \%$ of our sample. Therefore, it could be speculated that mutations in the SHOX enhancer region seem to be responsible mainly for bone deformities. In fact, both the homozygous case and her mother, who presented a heterozygous mutations in the SHOX enhancer region, showed bilateral Madelung deformity but not short stature.

The explanation of these findings probably is correlated with the etiology of the Madelung deformity, which originates with disorganized growth of part of the radial epiphysis, leading to radial bowing, premature fusion of that epiphysis, dorsal dislocation of the ulna, and wedged carpal bones. The premature fusion of the physis leads to cessation of longitudinal growth, and is always located in the ulnar zone of the distal radius but varies in the anteroposterior plane [32].

According to literature data, in our cohort, we did not find a correlation between bone defect, gender and the deletion size. These could be related to estrogens influence on the growth plate, which worse dyschondrosteosis leading to severe bone pain [33]. In this respect, it is interesting to underline that in this report many patients suffered from chronic widespread pain and received diagnosis of fibromyalgia. Since the pathogenesis of this musculoskeletal disorder is still unknown, a potential role of SHOX gene could be hypothesized, and further studies are required to clarify the relationship between SHOX deficit and fibromyalgia. In addition there isn't an age-dependent phenotype in these subjects.

\section{Conclusions}

In conclusion, the present report confirms the usefulness to perform SHOX analysis including the enhancer sequence in patients with elevated Rappold's score. In addition, it could be useful to follow-up these patients in 
order to verify the onset of fibromyalgia or other chronic idiopathic musculoskeletal disorders. Finally, the detection of a case of homozygous deletion of this region in a patient with severe bilateral Madelung deformity but a normal stature suggests the role of SHOX gene enhancer in contributing to different anomalies, which constitutes a wide spectrum of the disease. Therefore, the SHOX deficiency represents a complex and heterogeneous group of conditions ranging from the more severe phenotype (Langer syndrome) to milder forms (isolated short stature/isolated Madelung deformity).

\section{Consent}

Written informed consent was obtained from the patient for publication of this Case report and any accompanying images. A copy of the written consent is available for review by the Editor of this journal.

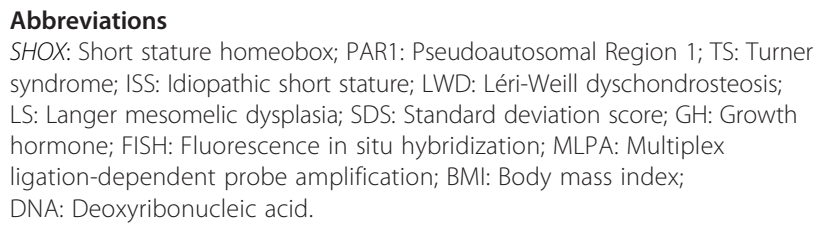

SHOX: Short stature homeobox; PAR1: Pseudoautosomal Region 1; TS: Turner syndrome; ISS: Idiopathic short stature; LWD: Léri-Weill dyschondrosteosis; LS: Langer mesomelic dysplasia; SDS: Standard deviation score; GH: Growth hormone; FISH: Fluorescence in situ hybridization; MLPA: Multiplex ligation-dependent probe amplification; BMI: Body mass index; DNA: Deoxyribonucleic acid

\section{Competing interests}

The authors declare that they have no competing and non-financial interests and also reveal any non-financial competing interests.

\section{Authors' contributions}

VG: contributed to conception and design, MLPA data analysis and drafted the manuscript. CP: responsible of clinical, participated in its design and coordination and drafted the manuscript. VC: responsible of clinical data and participated in its design and coordination. SF: performed the SHOX gene study through MLPA. GC, MS and ARC: responsible of radiographic studies. AM: responsible of clinical data and participated in its design and coordination. FC: helped to draft the manuscript. LS: have given final approval of the version to be published. All authors read and approved the final manuscript.

\section{Acknowledgements}

The authors did not count with any funding source. The authors did not have funding sources for the preparation of the manuscript nor for its publication.

\section{Author details \\ ${ }^{1}$ Department of Psychological, Humanities and Territory Sciences, School of Medicine and Health Sciences, "G. d'Annunzio" University of Chieti, via dei Vestini 31, 66013 Chieti, Italy. 'Center of Excellence on Aging, "G. d'Annunzio" University Foundation, via dei Vestini 31, 66013 Chieti, Italy. ${ }^{3}$ Department of Paediatrics, "G. d'Annunzio" University of Chieti, via dei Vestini 5, 66013 Chieti, Italy. ${ }^{4}$ Department of Neuroscience and Imaging, Section of Diagnostic Imaging and Therapy, Radiology Division, "G. d'Annunzio" University of Chieti, Chieti, Italy.}

Received: 31 March 2014 Accepted: 8 July 2014 Published: 23 July 2014

\section{References}

1. Ellison JW, Wardak Z, Young MF, Robey PG, Laig-Webster M, Chiong W: PHOG, a candidate gene for involvement in the short stature of Turner syndrome. Hum Mol Genet 1997, 6:1341-1347.

2. Belin V, Cusin V, Viot G, Girlich D, Toutain A, Moncla A, Vekemans M, Le Merrer M, Munnich A, Cormier-Daire V: SHOX mutations in dyschondrosteosis (Léri-Weill syndrome). Nat Genet 1998, 19:67-69.
3. Stuppia L, Calabrese G, Borrelli P, Gatta V, Morizio E, Mingarelli R, Di Gilio MC, Crinò A, Giannotti A, Rappold GA, Palka G: Loss of the SHOX gene associated with Léri-Weill dyschondrosteosis in a 45, X male. J Med Genet 1999, 36:711-713.

4. Calabrese G, Fischetto R, Stuppia L, Capodiferro F, Mingarelli R, Causio F, Rocchi M, Rappold GA, Palka G: X/Y translocation in a family with Léri-Weill dyschondrosteosis. Hum Genet 1999, 105:367-368.

5. Palka G, Stuppia L, Guanciali Franchi P, Chiarelli F, Fischetto R, Borrelli P, Giannotti A, Fioretti G, Rinaldi MM, Mingarelli R, Rappold GA, Calabrese G: Short arm rearrangements of sex chromosomes with haploinsufficiency of the SHOX gene are associated with Léri-Weill dyschondrosteosis. Clin Genet 2000, 57:449-453.

6. Rappold GA, Fukami M, Niesler B, Schiller S, Zumkeller W, Bettendorf M, Heinrich U, Vlachopapadoupoulou E, Reinehr T, Onigata K, Ogata T: Deletions of the homeobox gene SHOX (short stature homeobox) are an important cause of growth failure in children with short stature. J Clin Endocrinol Metab 2002, 87:1402-1406.

7. Chen J, Wildhardt G, Zhong Z, Röth R, Weiss B, Steinberger D, Decker J, Blum WF, Rappold G: Enhancer deletions of the SHOX gene as a frequent cause of short stature: the essential role of a $250 \mathrm{~kb}$ downstream regulatory region. J Med Genet 2009, 46:834-839.

8. Sabherwal N, Bangs F, Röth R, Weiss B, Jantz K, Tiecke E, Hinkel GK, Spaich C, Hauffa BP, van der Kamp H, Kapeller J, Tickle C, Rappold G: Longrange conserved non-coding SHOX sequences regulate expression in developing chicken limb and are associated with short stature phenotypes in human patients. Hum Mol Genet 2007, 16:210-222.

9. Morizio E, Stuppia L, Gatta V, Fantasia D, Guanciali Franchi P, Rinaldi MM, Scarano G, Concolino D, Giannotti A, Verrotti A, Chiarelli F, Calabrese G, Palka G: Deletion of the SHOX gene in patients with short stature of unknown cause. Am J Med Genet A 2003, 119A:293-296.

10. Stuppia L, Calabrese G, Gatta V, Pintor S, Morizio E, Fantasia D, Guanciali Franchi P, Rinaldi MM, Scarano G, Concolino D, Giannotti A, Petreschi F, Anzellotti MT, Pomilio M, Chiarelli F, Tumini S, Palka G: SHOX mutations detected by FISH and direct sequencing in patients with short stature. J Med Genet 2003, 40:E11.

11. Ross JL, Scott C Jr, Marttila P, Kowal K, Nass A, Papenhausen P, Abboudi J, Osterman L, Kushner H, Carter P, Ezaki M, Elder F, Wei F, Chen H, Zinn AR: Phenotypes associated with SHOX deficiency. J Clin Endocrinol Metab 2001, 86:5674-5680.

12. Jorge AA, Souza SC, Nishi MY, Billerbeck AE, Libório DC, Kim CA, Arnhold IJ, Mendonca BB: SHOX mutations in idiopathic short stature and Léri-Weill dyschondrosteosis: frequency and phenotypic variability. Clin Endocrinol (Oxf) 2007, 66:130-135.

13. Binder G, Ranke MB, Martin DD: Auxology is a valuable instrument for the clinical diagnosis of SHOX haploinsufficiency in schoolage children with unexplained short stature. J Clin Endocrinol Metab 2003, 88:4891-4896.

14. Niesler B, Röth R, Wilke S, Fujimura F, Fischer C, Rappold G: The novel human SHOX allelic variant database. Hum Mutat 2007, 28:933-938.

15. Binder G, Weidenkeller M, Blumenstock G, Langkamp M, Weber K, Franz AR: Rational approach to the diagnosis of severe growth hormone deficiency in the newborn. J Clin Endocrinol Metab 2010, 95:2219-2226.

16. Rappold G, Blum WF, Shavrikova EP, Crowe BJ, Roeth R, Quigley CA, Ross JL, Niesler B: Genotypes and phenotypes in children with short stature: clinical indicators of SHOX haploinsufficiency. J Med Genet 2007, 44:306-313.

17. Binder G: Short stature due to SHOX deficiency: genotype, phenotype, and therapy. Horm Res Paediatr 2011, 75:81-89.

18. Gatta V, Antonucci I, Morizio E, Palka C, Fischetto R, Mokini V, Tumini S, Calabrese G, Stuppia L: Identification and characterization of different SHOX gene deletions in patients with Léri-Weill dyschondrosteosys by MLPA assay. J Hum Genet 2007, 52:21-27.

19. Stuppia L, Gatta V, Antonucci I, Giuliani R, Palka G: Different approaches in the molecular analysis of the SHOX gene dysfunctions. J Endocrinol Invest 2010, 33:30-33.

20. Huber C, Rosilio M, Munnich A, Cormier- Daire V: French SHOX GeNeSIS Module: High incidence of SHOX anomalies in individuals with short stature. J Med Genet 2006, 43:735-739.

21. Stuppia L, Antonucci I, Palka G, Gatta V: Use of the MLPA Assay in the molecular diagnosis of gene copy number alterations in human genetic diseases. Int J Mol Sci 2012, 13:3245-3276.

22. Fukami M, Kato F, Tajima T, Yokoya S, Ogata T: Transactivation function of an approximately 800-bp evolutionarily conserved sequence at the 
SHOX 3' region: implication for the downstream enhancer. Am J Hum Genet 2006, 78:167-170.

23. Fukami M, Dateki S, Kato F, Hasegawa Y, Mochizuki H, Horikawa R, Ogata T: Identification and characterization of cryptic SHOX intragenic deletions in three Japanese patients with Léri-Weill dyschondrosteosis. $J$ Hum Genet 2008, 53:454-459.

24. Durand C, Bangs F, Signolet J, Decker E, Tickle C, Rappold G: Enhancer elements upstream of the SHOX gene are active in the developing limb. Eur J Hum Genet 2010, 18:527-532.

25. Kenyon EJ, McEwen G, Callaway H, Elgar G: Functional analysis of conserved noncoding regions around the short Stature hox Gene (shox) in whole zebrafish embryos. PLoS One 2011, 6:e21498.

26. Benito-Sanz S, Royo JL, Barroso E, Paumard-Hernández B, Barreda-Bonis AC, Liu P, Gracía R, Lupski JR, Campos-Barros Á, Gómez-Skarmeta JL, Heath KE: Identification of the first recurrent PAR1 deletion in Léri-Weill dyschondrosteosis and idiopathic short stature reveals the presence of a novel SHOX enhancer. J Med Genet 2012, 49:442-450.

27. Caliebe J, Broekman S, Boogaard M, Bosch CA, Ruivenkamp CA, Oostdijk W. Kant SG, Binder G, Ranke MB, Wit JM, Losekoot M: IGF1, IGF1R and SHOX mutation analysis in short children born small for gestational age and short children with normal birth size (idiopathic short stature). Horm Res Paediatr 2012, 77:250-260

28. Kant SG, Broekman SJ, de Wit CC, Bos M, Bos M, Scheltinga SA, Bakker E, Oostdijk W, van der Kamp HJ, van Zwet EW, van der Hout AH, Wit JM, Losekoot M: Phenotypic characterization of patients with deletions in the 3'-flanking SHOX region. Peer J 2013, 19:1:e.

29. Schiller S, Spranger S, Schechinger B, Fukami M, Merker S, Drop SL, Tröger J, Knoblauch H, Kunze J, Seidel J, Rappold GA: Phenotypic variation and genetic heterogeneity in Léri-Weill syndrome. Eur J Hum Genet 2000, 8:54-62.

30. Marchini A, Marttila T, Winter A, Caldeira S, Malanchi I, Blaschke RJ, Häcker B, Rao E, Karperien M, Wit JM, Richter W, Tommasino M, Rappold GA: The short stature homeodomain protein SHOX induces cellular growth arrest and apoptosis and is expressed in human growth plate chondrocytes. J Biol Chem 2004, 279:37103-37114

31. Munns CJ, Haase HR, Crowther LM, Hayes MT, Blaschke R, Rappold G, Glass IA, Batch JA: Expression of SHOX in human fetal and childhood growth plate. J Clin Endocrinol Metab 2004, 89:4130-4135.

32. Munns CF, Glass IA, LaBrom R, Hayes M, Flanagan S, Berry M, Hyland VJ, Batch JA, Philips GE, Vickers D: Histopathological analysis of Léri-Weill dyschondrosteosis: disordered growth plate. Hand Surg 2001, 6:13-23.

33. Ogata T: SHOX: pseudoautosomal homeobox containing gene for short stature and dyschondrosteosis. Growth Horm IGF Res 1999, 9(Suppl B):53-57.

doi:10.1186/1471-2350-15-87

Cite this article as: Gatta et al:: Spectrum of phenotypic anomalies in four families with deletion of the SHOX enhancer region. BMC Medical Genetics 2014 15:87.

\section{Submit your next manuscript to BioMed Central and take full advantage of:}

- Convenient online submission

- Thorough peer review

- No space constraints or color figure charges

- Immediate publication on acceptance

- Inclusion in PubMed, CAS, Scopus and Google Scholar

- Research which is freely available for redistribution 